\title{
On a Chemical Peculiarity of the Dimorphic Anthers of Lagerstroemia indica, with a Suggestion as to its Ecological Significance.
}

BY

\section{J. ARTHUR HARRIS. \\ With two Figures in the Text. \\ I. INTRODUCTORY REMARKS.}

BOUT ten years ago I observed certain peculiarities in the dimorphic indica, which seemed worthy of detailed investigation, but the results of studies made in 1903, I904, and I905 at the Missouri Botanical Garden have lain among my notes since that time because $I$ have hoped to be able to verify the essential points and to fill in the lacunae. At present I see no prospect of doing anything further with the problem. Nor do I know personally any one who might take my data and complete the work. It seems only right, therefore, to publish the results attained for the benefit of any one who may have the inclination and the opportunity to do the work more thoroughly.

\section{Floral Structure and Anthesis.}

Briefly described, the structure of the flower is as follows: The petals are unguiculate, with an oval to orbicular crispate limb. The numerous stamens have filiform filaments and elliptical anthers with pulviniform connectives. The greater number of the stamens are bright yellow in colour, but one in front of each sepal is usually larger, both as to filament and anther, and of a reddish instead of a yellow colour. In young buds the anthers are not distinguishable by their colour, both kinds being a light yellow. The characteristic colours are developed as the buds grow older. A detailed study of the numerical relationships of the parts of the flower has been given elsewhere. ${ }^{1}$

The flowers open as a rule about half-past eight o'clock in the morning, although there is great variation in this regard, occasional flowers opening as late as five or six in the evening.

1 Harris, J. Arthur: Variation and Correlation in the Flowers of Lagerstroemia indica. Ann. Report Mo. Bot. Gard., vol. xx, 1909, pp. 97-104.

[Annals of Botany, Vol. XXVIII. No. CXI. July, 1914.] 
Upon the opening of the flower the filaments of the smaller stamens turn somewhat upwards, while the pistil is turned in the opposite direction, downwards, for the greater part of the length, but the tip is turned somewhat upward. The larger stamens bend outward proximally but curve in distally, bringing the large anthers towards each other.

These large anthers open by two introrse longitudinal slits soon (perhaps half an hour) after anthesis; their pollen forms two bright green or yellowish-green lines, in sharp contrast to the reddish ground colour of the anther, which darkens with age. The pollen is very freely and readily shed, adhering to any object brushed lightly against the surface of the opened anther.

The smaller anthers do not dehisce until about half an hour after the red ones; their pollen does not leave the cells so rapidly, and when examined microscopically generally does not appear as much shrunken by drying.

The red anthers fall first, generally about eight or ten hours after the flower opens. The yellow anthers often remain on the filaments until the second day. As far as observed, both types fall spontaneously. No insect has been observed eating entirely either type, as has been described for some other forms of pollen flowers.

\section{iII. Physiological Peculiarities of the Anthers.}

The difference in the time of dehiscence of the two types of anthers, the fact that the larger anthers seemed to fall before the smaller, and especially the observation that their pollen seems more dry and powdery, and when microscopically examined appears more shrunken, suggested the desirability of more detailed and accurate observations to determine the nature of these phenomena.

The most plausible explanation for the peculiarities observed would seem to be a difference in the rate of evaporation of water. Two simple experiments proved the correctness of the hypothesis. (a) When red and yellow anthers were placed close together on a slide and their pollen crushed out simultaneously and spread out over the glass and examined under the microscope, the pollen from the red anthers dried more rapidly than that from the yellow. (b) The necessity of the frequent readjustment of the balance on the pans, of which lots of red and yellow anthers were exposed to the air in watch-glasses, showed that the two lots were decreasing in weight at different rates, and that the red anthers were losing more rapidly than the yellow.

A series of careful parallel weighings was then undertaken to determine as nearly as possible the difference in the rate of evaporation. ${ }^{1}$

1 There are two possible sources of error in my work. All my material came from plants kept under glass in winter and transferred to the open for the summer. This might, as Darwin suggested 
For these experiments material was collected in the morning between eight and nine o'clock. Buds which were ready to open, or flowers which had just opened, were selected. In no case were anthers which had begun to dehisce employed for weighings.

For each comparison the weighings of the two types of anthers were made at approximately the same intervals of time. Conditions probably differed somewhat from series to series, but since they were the same for both kinds of anthers in any one lot, the comparison may be considered satisfactory. The general qualitative results of every individual experiment were unquestionably the same. Exact comparisons of the curves obtained for the different examinations is a matter of little importance for our immediate purposes.

In the tables ${ }^{1}$ are given the actual weights of the masses of red and yellow anthers at different times, the absolute decrease of the weight at the last recording, and the percentage decrease calculated on the basis of the original weight. ${ }^{2}$

It is clear that if the red anthers lose water more rapidly than the yellow, their percentage loss will, in the early weighings, be greater than that of the yellow. If both series are practically completely desiccated, it is also clear that in the later periods the yellow must lose a higher percentage of their original moisture than the red, since the latter must have lost the greater part of their water early in the process of desiccation. A study of the tables shows this to be the case. The exact quantitative relationships vary greatly from table to table, as must be expected from the diversity of method in the carrying out of the weighings. Notwithstanding these inequalities the rule holds without exception for both published and unpublished experiments.

The best method of comparison is to sum the percentage of water lost by each type of anther up to, and including, any given weighing. The results of such summations are shown graphically for series $A-C$, in which

in his observations on this species, be a factor of some importance. Of course, the Orient would be the best place for such studies, but the Southern States, where the species is hardy out of doors throughout the year, would afford much better material than our northern gardens.

Again, the anthers are minute and the weighings upon which our conclusions rest must be done on very small masses of material, which to be of value must be collected with great rapidity. I am under the greatest obligation to Mr. Dean H. Rose and to Miss Olive Kerley for the exceedingly exacting routine work. If subsequent observers find errors in our work, or conclusions, they are to be attributed to me rather than to my two assistants, who were most conscientious and more deft and rapid in the manipulation of chemical balances than $\mathrm{I}$.

1 Table A gives the results of one of six series of weighings carried out by Mr. Rose. The remaining five series of comparative weighings made by him led' to the same results and are not published. The data of the other tables are due to Miss Kerley.

2 These tables are of two kinds. In A-C the loss every few minutes (except as noted) for a period of several hours is recorded. In D-G fewer weighings were made over a longer period of time, the anthers being allowed to become nearly or quite air dry. Experiments B and C were also carried over to the second day; hence in these cases, the summed percentage loss up to certain selected intervals is included for the sake of comparison in the second set of tables. 
Harris.-On a Chemical Peculiarity of the

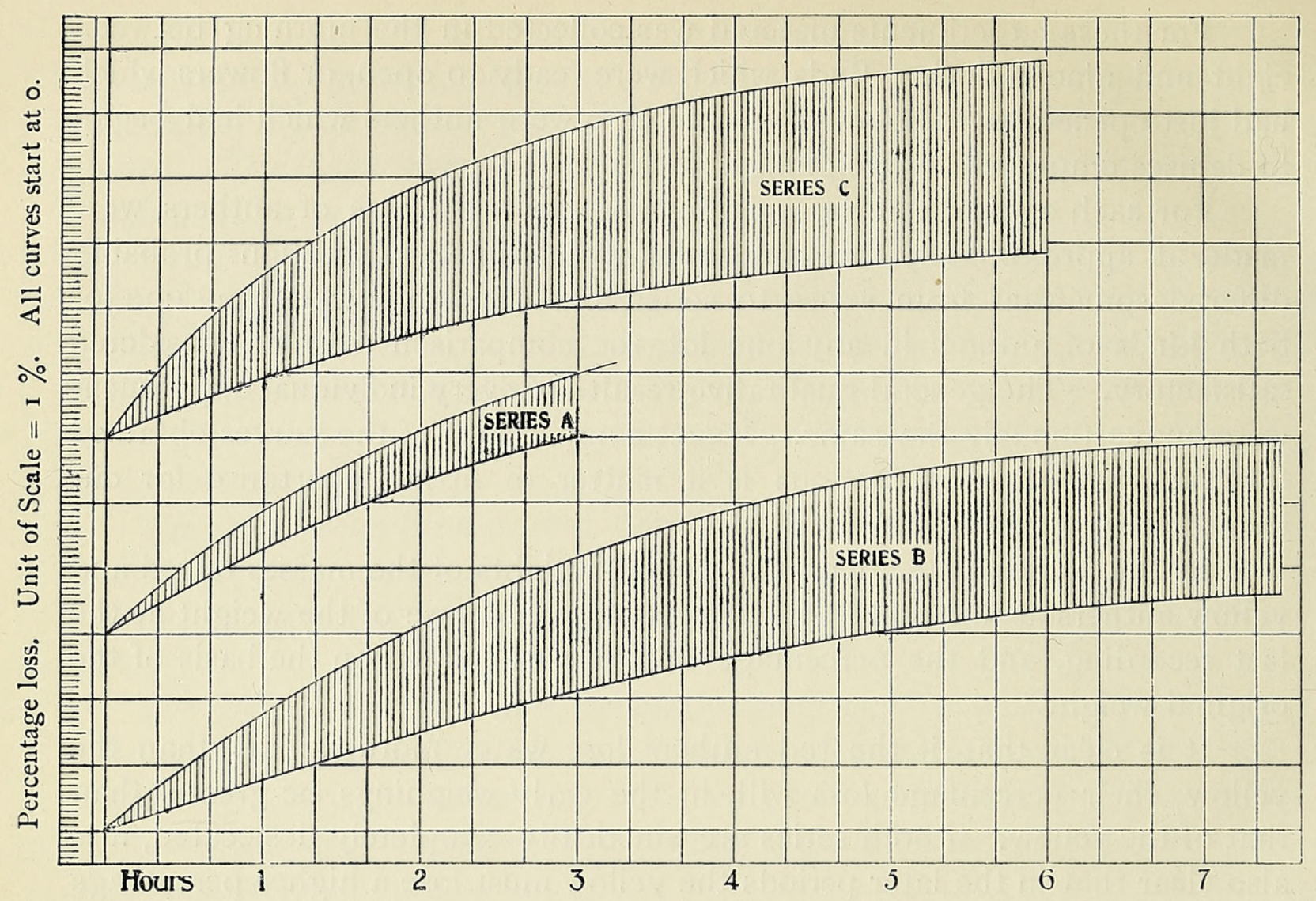

FIG. I.

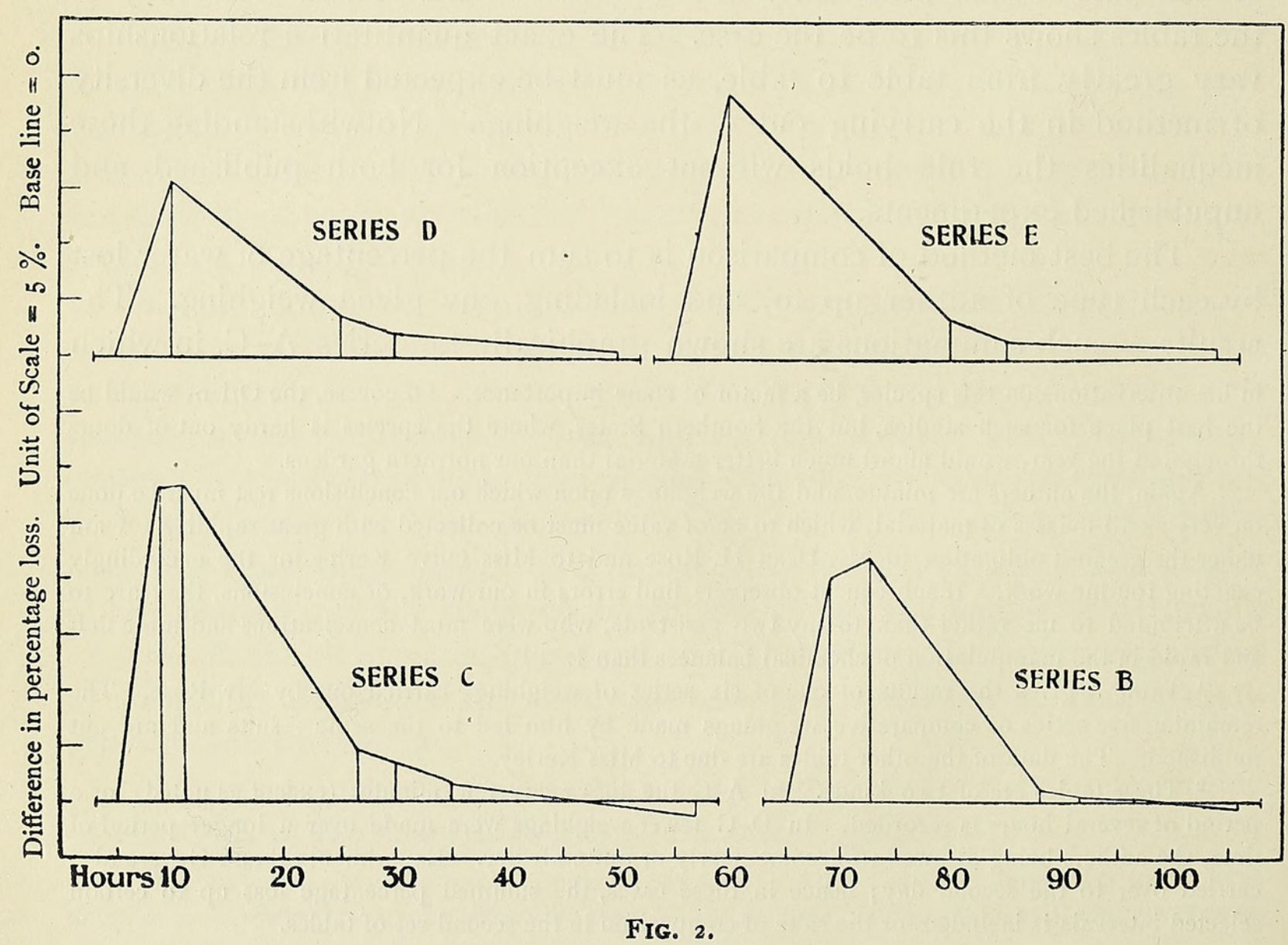


weighings were made every few minutes, in Fig. I. The rate of loss for the red anthers is represented by the upper curve, while the rate for the yellow anthers is shown by the lower one. The difference in the total relative water loss of the two types of anthers is clearly shown by the (shaded) difference between the two curves. ${ }^{1}$ In each case the red anthers lose far more rapidly than the yellow.

Such loss cannot of course continue indefinitely. After the red anthers have lost a considerable part of their water, the rate of loss from the other type must become higher, until finally both types are air dry. This is clearly shown in a second set of diagrams, Fig. 2. In these the abscissae represent hours, while the heights of the ordinates erected at various intervals show the percentage loss of water by the red anthers minus the percentage loss by the yellow anthers. After a few hours the loss by the red anthers is far in excess of that by the yellow. Finally, the difference becomes practically zero.

\section{Nature of the Physiological Differentiation OF ANTHERs.}

The immediately underlying cause of the physiological peculiarities which have been demonstrated to characterize the morphologically differentiated anthers must be either physical or chemical.

Possible physical factors are dissimilarities in form, resulting in the exposure of widely different surfaces to evaporation, or differences in the histology of the superficial layers, which are capable of modifying the amount of water lost by evaporation. Both types of anthers are of roughly the same form. I have not made critical histological cumparisons, but the sections I have seen indicate that there are at least no conspicuous differences between the two types.

Thus, comparatively considered, the evidence for a physical basis of the observed differences is quite negative. Quantitatively examined, the data are strongly opposed to such an assumption. The large anthers are of about the same form as the small ones. The ratio of the surfaces of the two types of anthers will be closely enough

$$
\text { Sr:Sy:: }(\sqrt[3]{V r})^{2}:(\sqrt[3]{V y})^{2}
$$

where $V r, V y$ are the volumes of the red and yellow anthers respectively. Volume may for all practical purposes be taken as the equivalent of weight, provided the two types of anthers have the same percentage water content.

In the experiments entered in Tables $\mathrm{A}-\mathrm{C}$ the anthers were not allowed to dry completely; hence the total water lost by the red is far in

1 These are merely draughtsman's curves, secured by fitting a spline as closely as possible to the data given in the tables. 
excess of that lost by the yellow. In the illustrative series B-G the anthers were more nearly completely air-dried. The results are :

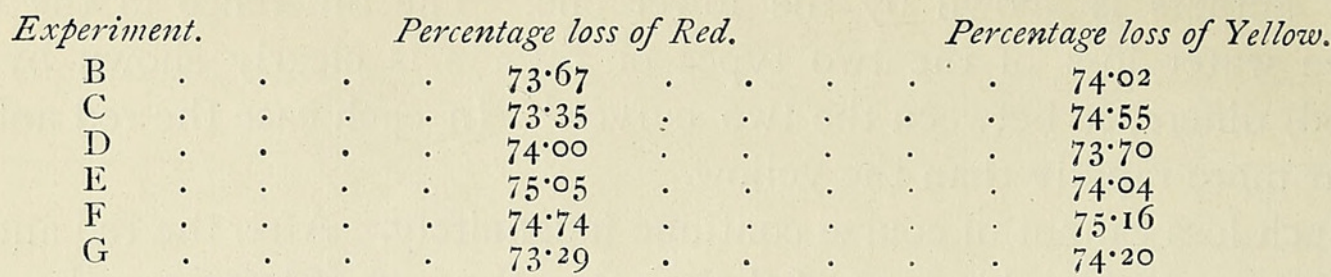

In view of the technical difficulties involved, no significance is to be attached to these differences. ${ }^{1}$ The density of the two types of anthers may be taken as about the same. Their volume may be regarded as directly proportional to their weight. The average weights are :

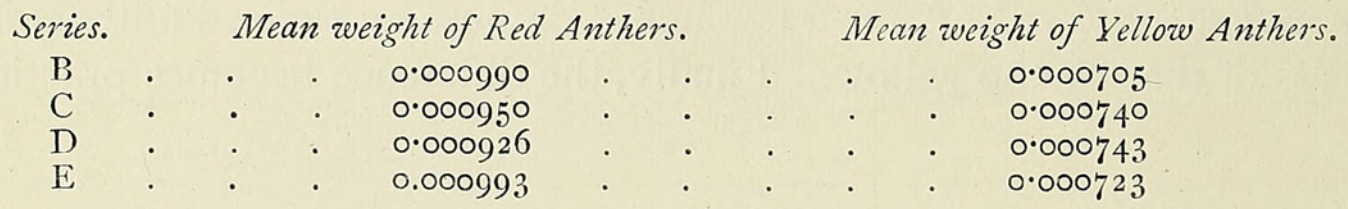

Thus there is a considerable difference in volume, which means a considerably lower ratio of surface to volume in the red anthers. This should, on purely physical grounds, be followed by a lower rate of evaporation from the large anthers. Instead, a higher initial rate obtains.

Besides these convincing evidences against the physical nature of the physiological peculiarities of the anthers, there are many indications that there is some chemical substance in the small anthers which by its presence (or by its relatively greater abundance as compared with the large anthers) limits the loss of water. The data upon which this statement is based are drawn from experiments in the loss of water, and from those on the reabsorption of water by anthers which had been washed or boiled in water, or extracted with alcohol and ether and dried. These experiments I do not care to describe in further detail, since I believe that the difficulties incurred were beyond our skill, and that the quantitative data we secured are not worth publication. That the results are due to some substance occurring only, or in much greater abundance, in the smallest anthers, I have not the slightest doubt.

\section{Ecological Relationshitis of Flower.}

Bees were observed as visitors, collecting pollen from the small yellow anthers, but as far as could be observed, almost without exception, taking no notice of the large ones, which are of a colour very similar to that of the unguiculate petals. The following species, kindly determined by Mr. Charles

1 Drying on a bath gives a higher percentage loss of water, but there is no clear evidence from several determinations that there are any constant differences in the relative water content of the two types. 
Robertson, whose work on floral ecology and on bees is well known, were taken :

Megachile mendica, $\mathrm{Cr}$. $q$

Megachile generosa, $\mathrm{Cr}$. \&

Bombus scutellaris, Cr. (B. fraternus, Sm.) के

Bombus americanorum, Cr. (B. pennsylvanicus, De G.) ‡

Chloralictus versatus, Rob., seems to visit the larger stamens frequently, but was also observed on the smaller stamens.

Apis mellifera, L. $\Varangle$

Agapostemon radiatus, Say. $q$

\section{Summary and Discussion of Observations.}

In the Malayan shrub, Lagerstroemia indica, the stamens are dimorphic, those of the outer whorl being larger than the more central yellow group, and differing from them not only in colour, but, as Darwin showed, in the pollen which they contain.

Quantitatively, the two types of anthers bear the size (weight) ratio of about $\mathrm{I} \cdot 3: \mathrm{I}$. The filaments of the large-anthers are about $5^{-6}$ times as large (heavy) as those of the small ones.

The observations described in this paper show that the differentiation is not merely morphological, but that it is physiological as well. The larger (outer) anthers lose water much more rapidly by evaporation than do the smaller ones. The total loss is finally sensibly the same in the two types.

The underlying cause of the physiological differentiation seems to be chemical rather than physical. The large anthers present, in comparison with their volume, a smaller surface from which evaporation can take place, and should in consequence be expected to show a lower, instead of a higher initial water loss. Furthermore, there is no conspicuous difference in the histology of the superficial layers of cells of the two types of anthers. On the other hand, there appears to be a water-soluble substance occurring only, or in greater abundance, in the smaller anthers which lowers their rate of water loss. The nature of this substance is quite unknown.

The ecological consequence ${ }^{1}$ of the physiological differentiation is that the pollen of the larger anthers (which are borne on longer filaments, incurved in a manner to bring them in contact with the body of a visiting insect) is dry and powdery soon after the opening of the flower, and easily scattered over the body of a visiting insect, whereas that of the smaller anthers remains for a much longer time moist, and easily massed by the bees, which collect it in large quantities.

1 I have reviewed elsewhere (loc. cit.) the literature of the biology of the flower of this form. It seems unnecessary to go over once more the points in detail. 
The morphological and physiological dimorphism is, from the evidences at hand, as clear a case of specialization of parts to facilitate pollination as many others which have been described in the vast literature of floral ecology. The central yellow mass of anthers of the nectarless flowers furnishes the booty to the visiting insects, in a form which does not require moistening (or as much moistening, as in the case of the pollen of many other flowers) in massing for transportation. The outer whorl of anthers which are inconspicuous, because isochromatic with the corolla, furnish the dry powdery pollen for fertilization. Unfortunately for the theory of adaptation, the pollen from both types of anthers will, according to Müller, produce seed. Personally, I feel that this and other interesting problems concerning the anther morphology and physiology of this species must await studies in its natural environment.

Cold Spring Harbour, N.Y.,

fan. $26, \mathrm{I} 9[4$.

TABLE A.

\begin{tabular}{|c|c|c|c|c|c|c|c|c|c|}
\hline \multirow{2}{*}{\multicolumn{2}{|c|}{ Hour. }} & \multicolumn{3}{|c|}{ Red Anthers. } & \multirow{2}{*}{\multicolumn{2}{|c|}{ Hour. }} & \multicolumn{3}{|c|}{ Yellow Anthers. } \\
\hline & & Weight. & Loss. & \% Loss. & & & Weight. & Loss. & $\%$ Loss. \\
\hline 8.40 & A.M. & 0.0300 & - & - & 8.40 & A. M. & 0.0471 & 一 & - \\
\hline 8.55 & , & 0.0285 & 0.0015 & $5 \cdot 00$ & 8.50 & , & 0.0460 & $0.001 \mathrm{I}$ & $2 \cdot 33$ \\
\hline 9.05 & ", & 0.0273 & 0.0012 & 4.00 & 9.05 & " & $0.045^{\circ}$ & 0.0010 & $2 \cdot 12$ \\
\hline 9.15 & , & 0.0264 & 0.0009 & $3 \cdot 00$ & 9.20 & , & 0.0434 & 0.0016 & $3 \cdot 39$ \\
\hline 9.25 & ", & 0.0256 & 0.0008 & $2 \cdot 66$ & $9 \cdot 3 \circ$ & , & 0.0425 & 0.0009 & $I \cdot 9 I$ \\
\hline $9 \cdot 35$ & " & 0.0248 & 0.0008 & $2 \cdot 66$ & $9 \cdot 40$ & " & $0.04 I_{5}$ & 0.0010 & $2 \cdot$ I I \\
\hline $9 \cdot 45$ & " & 0.0243 & 0.0005 & ] 66 & $9 \cdot 50$ & ", & 0.0405 & 0.0010 & $2 \cdot 1 \mathrm{I}$ \\
\hline $9 \cdot 55$ & ", & 0.0232 & $0.001 \mathrm{I}$ & $3 \cdot 66$ & 10.0 & $"$ & 0.0402 & 0.0003 & 0.63 \\
\hline 10.05 & ", & 0.0227 & 0.0005 & $1 \cdot 66$ & 10.10 & $"$ & 0.0392 & 0.0010 & $2 \cdot$ I I \\
\hline 10.15 & , & 0.0219 & 0.0008 & $2 \cdot 66$ & 10.20 & , & 0.0383 & 0.0009 & $I \cdot 9 I$ \\
\hline 10.25 & ", & $0.02 \mathrm{I}_{4}$ & 0.0005 & $I \cdot 66$ & 10.30 & , & 0.0376 & 0.0007 & $1 \cdot 48$ \\
\hline 10.35 & ," & 0.0209 & 0.0005 & $I \cdot 66$ & 10.40 & ,, & 0.0368 & 0.0008 & $\mathrm{I} \cdot 69$ \\
\hline 10.45 & ", & 0.0203 & 0.0006 & $2 \cdot 00$ & $10.5^{\circ}$ & ", & 0.0362 & 0.0006 & $I \cdot 27$ \\
\hline 10.55 & ," & 0.0196 & 0.0007 & $2 \cdot 33$ & II.O & ", & 0.0355 & 0.0007 & $\mathrm{I} \cdot 4^{8}$ \\
\hline I I.25 & , & $0.018_{4}$ & 0.0012 & $4^{\circ} \cdot 00$ & I I.20 & ,, & 0.0346 & 0.0009 & $I \cdot 9 I$ \\
\hline II. 55 & , & $0.017 \mathrm{I}$ & 0.0013 & $4 \cdot 33$ & I $1.5^{\circ}$ & , & 0.0328 & 0.0018 & $3 \cdot 82$ \\
\hline
\end{tabular}

TABLE B.

\begin{tabular}{|c|c|c|c|c|c|c|c|c|}
\hline Hour. & \multicolumn{3}{|c|}{ Red Anthers. } & $\mathrm{Hor}$ & $u r$. & Yellow Anthers. & $\begin{array}{c}\text { w Anth } \\
\text { Loss. }\end{array}$ & Los. \\
\hline 9. I 5 A.M. & 0.0396 & - & - & 9.20 & A.M. & 0.0282 & - & 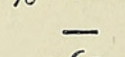 \\
\hline 9.45, & $0.035^{2}$ & 0.0044 & I I I I I & $9.5^{\circ}$ &, & 0.0269 & 0.0013 & $4^{\cdot 6 I}$ \\
\hline 10.15, & 0.0320 & 0.0032 & $8 \cdot 08$ & 10.20 & , & 0.0258 & 0.0011 & $3 \cdot 90$ \\
\hline 10.45, & 0.0298 & 0.0022 & $5 \cdot 55$ & 10.50 & , & 0.0250 & 0.0008 & $2 \cdot 83$ \\
\hline II.I 5, & 0.0277 & $0.002 \mathrm{I}$ & $5 \cdot 30$ & II.20 & , & 0.0240 & 0.0010 & $3 \cdot 54$ \\
\hline I I.45, , & 0.0254 & 0.0023 & $5 \cdot 80$ & II. 50 & ", & 0.0233 & 0.0007 & $2 \cdot 4^{8}$ \\
\hline I. I5 P.M. & 0.0214 & 0.0040 & $10 \cdot 10$ & I. 20 & P.M. & 0.0209 & 0.0024 & $8 \cdot 5 \mathrm{I}$ \\
\hline 1.45, & 0.0204 & 0.0010 & $2 \cdot 5^{2}$ & I. 50 & , & 0.0206 & 0.0003 & $1 \cdot 06$ \\
\hline 2.15, & o.0194 & 0.0010 & $2 \cdot 52$ & 2.20 & ” & 0.0200 & 0.0006 & $2 \cdot 12$ \\
\hline 2.45, & 0.0180 & 0.0014 & $3 \cdot 53$ & 2.50 & " & 0.0194 & 0.0006 & $2 \cdot 12$ \\
\hline 3.15, & 0.0177 & 0.0003 & 0.75 & 3.20 & , & 0.0189 & 0.0005 & $1 \cdot 77$ \\
\hline 3.45, & 0.0172 & 0.0005 & $1 \cdot 26$ & 3.50 & ", & 0.0183 & 0.0006 & $2 \cdot 12$ \\
\hline 4.15, & 0.0164 & 0.0008 & $2 \cdot 02$ & 4.20 & , & 0.0130 & 0.0003 & $1 \cdot 06$ \\
\hline 4.45, & 0.0160 & 0.0004 & $I \cdot O I$ & $4 \cdot 50$ & , & 0.0176 & 0.0004 & $I \cdot 4 I$ \\
\hline
\end{tabular}


TABLE C.

\begin{tabular}{|c|c|c|c|c|c|c|c|c|}
\hline \multirow{2}{*}{ Hour. } & \multicolumn{3}{|c|}{ Red Anthers. } & \multirow{2}{*}{\multicolumn{2}{|c|}{ Hour. }} & \multicolumn{3}{|c|}{ Yellow Anthers. } \\
\hline & Weight. & Loss. & $\%$ Loss. & & & Weight. & Loss. & $\%$ Loss. \\
\hline A.M. & 0.0380 & - & - & 10.35 & A.M. & 0.0296 & - & - \\
\hline , & 0.0321 & 0.0059 & $15 \cdot 52$ & I I. 05 & $"$ & 0.0282 & 0.0014 & $4 \cdot 73$ \\
\hline 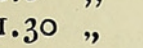 & 0.0286 & 0.0035 & $9 \cdot 21$ & I I. 35 &, & 0.0269 & 0.0013 & $4 \cdot 39$ \\
\hline P.M. & 0.0206 & 0.0080 & $2 \mathrm{I} \cdot 05$ & 1.35 & P.M. & $0.023 I$ & 0.0033 & I I I I 4 \\
\hline, & 0.0194 & 0.0012 & $3 \cdot 15$ & 2.05 & , & 0.0225 & 0.0006 & 2.02 \\
\hline , & 0.0184 & 0.0010 & $2 \cdot 63$ & 2.3 & , & 0.0220 & 0.0005 & $1 \cdot 67$ \\
\hline , & 0.0170 & 0.0014 & 3.68 & 3.05 & , & 0.0215 & 0.0005 & $I \cdot 67$ \\
\hline , & 0.0164 & 0.0006 & $1 \cdot 58$ & $3 \cdot 35$ & $"$ & 0.0210 & 0.0005 & $1 \cdot 67$ \\
\hline ", & 0.0159 & 0.0005 & $1 \cdot 3 I$ & 4.05 & , & 0.0206 & 0.0004 & $I \cdot 35$ \\
\hline " & 0.0154 & 0.0005 & $I \cdot 3 I$ & $4 \cdot 35$ & , & 0.0200 & 0.0006 & $2 \cdot 02$ \\
\hline
\end{tabular}

\section{TABLES D-G.}

Exp. Date and Hour.

Ang. Ioth, 9.I 5 A.M.

I.I 5 P.M.

B Ang. IIth, 8.0 A.M. II.40

Aug. I 2th, 2.0 ,

Aug. Ioth, I0.32 A.M.

2.33 P.M.

4.32 ,

C Aug. IIth, 8.05 A.M. I I.45 ,

$4.5^{\circ}$ P.M.

Ang. I 2th, 2.05,

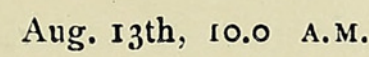

D Aug. I $4^{\text {th }}$, I I.0 ",

$$
4.0 \text { P.M. }
$$

Aug. I5th, I $2.0 \mathrm{M}$.

Aug. $13^{\text {th }}$, I0.30 A.M. $3.3 \circ$ P.M.

E Aug. I $4^{\text {th }}$, I 1.30 A.M. 4.30 P.M.

Aug. I 5th, I I.30 A.M.

Aug. I8th, IO.I5 A.M. 3.0 P.M.

F Aug. I9th, II.0 A.M. 4.0 P. M.

Aug. 2oth, I 2.0 M.

Ang. I 8th, I 0.30 A.M. 3.30 P.M.

G Aug. I9th, I I.3० A.M. 4.30 P.M.

Aug. 20th, 1 2.30 ,
Red Anthers.

Weight. Loss. \% Loss. 0.0396

0.0214

0.0110

0.0107

0.0104

0.0104

0.0380

0.0184

0.0154

0.0105

0.0103

0.0102

0.0101

0.0250

0.0126

0.0072

0.0070

0.0065

0.0397

0.0175

0.0109

0.0108

0.0100

$\begin{array}{cc}0.0040 & 10.10 \\ 0.0004 & I \cdot 01 \\ 0.0050 & 12.62 \\ 0.0003 & 0.75 \\ 0.0003 & 0.75 \\ 0.0000 & 0.00\end{array}$

0.00

$\begin{array}{cc}- & - \\ 0.0010 & 2.63 \\ 0.0005 & 1.31 \\ 0.0049 & 12.89 \\ 0.0002 & 0.5^{2} \\ 0.0001 & 0.25 \\ 0.0001 & 0.25\end{array}$

0.0124

0.0054

0.0002

0.0005

$\overline{49 \cdot 60}$
$21 \cdot 60$
0.80
$2 \cdot 00$

$-$

0.0223

0.0001

0.0008

$56 \cdot 17$
16.62
0.25
$2 \cdot 0.1$

0.0444

0.02 I 3

0.0112

0.0112

0.01 I 2

$0.04 \mathrm{I} 2$

0.0218

0.0102

0.0100

0.0100

$\begin{array}{cc}- & - \\ 0.0231 & 52.00 \\ 0.0101 & 22.74 \\ 0.0000 & 0.00 \\ 0.0000 & 0.00\end{array}$

$\begin{array}{cr}- & - \\ 0.0194 & 47.08 \\ 0.0106 & 25.72 \\ 0.0002 & 0.48 \\ 0.0000 & 0.00\end{array}$

Yellow Anthers.

Weight. Loss. \% Loss.

$\begin{array}{lcr}0.0282 & - & - \\ 0.0209 & 0.0024 & 8.5 \text { I } \\ 0.0176 & 0.0004 & \text { I.4I } \\ 0.0083 & 0.0093 & 32.97 \\ 0.0077 & 0.0006 & 2.12 \\ 0.0075 & 0.0002 & 0.70 \\ 0.0073 & 0.0002 & 0.70\end{array}$

0.0296
0.0220
0.0200
0.0090
0.0084
0.0079
0.0070
0.0312
0.0207
0.0102
0.0095
0.0082

0.0005
0.0006

0.0006
0.0110

0.0006

0.0005

0.0009

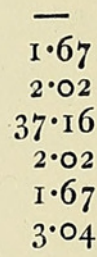

0.0105 0.0105 0.0007 0.0013

$33 \cdot 65$ $33 \cdot 65$

$2 \cdot 24$ $4 \cdot 16$

0.0347
0.0235
0.0105
0.0098
0.0090
0.0411
0.0284
0.0107
0.0104
0.0102
0.0353
0.0230
0.0094
0.0092
0.0091

0.011 0.0130 0.0007 0.0008

$32 \cdot 27$ $37 \cdot 46$ $2 \cdot 0 \mathrm{I}$ $2 \cdot 30$

$\begin{array}{lr}- & - \\ 0.0127 & 30.90 \\ 0.0177 & 43.06 \\ 0.0003 & 0.72 \\ 0.0002 & 0.48\end{array}$

$0.0123 \quad \overline{34.84}$ $0.0136 \quad 38.52$ $0.0002 \quad 0.56$ $0.0001 \quad 0.28$ 


\section{$2 \mathrm{BHL}$ Biodiversity Heritage Library}

Harris, J Arthur. 1914. "On a chemical peculiarity of the dimorphic anthers of Lagerstroemia indica, with a suggestion as to its ecological significance." Annals of botany 28, 499-507. https://doi.org/10.1093/oxfordjournals.aob.a089517.

View This Item Online: https://www.biodiversitylibrary.org/item/236856

DOI: https://doi.org/10.1093/oxfordjournals.aob.a089517

Permalink: https://www.biodiversitylibrary.org/partpdf/320035

\section{Holding Institution}

Smithsonian Libraries

\section{Sponsored by}

Biodiversity Heritage Library

\section{Copyright \& Reuse}

Copyright Status: Not in copyright. The BHL knows of no copyright restrictions on this item.

This document was created from content at the Biodiversity Heritage Library, the world's largest open access digital library for biodiversity literature and archives. Visit BHL at https://www.biodiversitylibrary.org. 